\title{
Multiple endocrine neoplasia type 1 in Northern Finland; clinical features and genotype-phenotype correlation
}

\author{
O Vierimaa, T M L Ebeling ${ }^{1}$, S Kytölä ${ }^{2}$, R Bloigu ${ }^{3}$, E Eloranta ${ }^{1}$, J Salmi ${ }^{4}$, E Korpi-Hyövälti ${ }^{5}$, L Niskanen ${ }^{6}$, A Orvola ${ }^{7}$, \\ E Elovaara $^{8}$, A Gynther ${ }^{9}$, T Sane ${ }^{10}$, M Välimäki ${ }^{10}$, J Ignatius, J Leisti and P I Salmela ${ }^{1}$ \\ Department of Clinical Genetics, Oulu University Hospital, PB 24, FIN-90029 Oys, Oulu, Finland, ${ }^{1}$ Department of Internal Medicine, Oulu University \\ Hospital, FIN-90029 Oys, Oulu, Finland, ${ }^{2}$ Medix Laboratories Ltd, FIN-02630 Espoo, Finland, ${ }^{3}$ Department of Medical Informatics, Faculty of Medicine, \\ FIN-90014 Oulu University, Oulu, Finland, ${ }^{4}$ Department of Internal Medicine, Tampere University Hospital, FIN-33014 Tampere, Finland, ${ }^{5}$ Department \\ of Internal Medicine, Seinäjoki Central Hospital, FIN-60220 Seinäjoki, Finland, ${ }^{6}$ Department of Medicine, Kuopio University Hospital, FIN-70211 \\ Kuopio, Finland, ${ }^{7}$ Department of Medicine, Central Hospital of Kanta-Häme, FIN-13530 Hämeenlinna, Finland, ${ }^{8}$ Department of Medicine, Central \\ Hospital of Pohjois-Karjala, FIN-80210 Joensuu, Finland, ${ }^{9}$ Department of Medicine, Central Hospital of Mikkeli, FIN-50100 Mikkeli, Finland and \\ ${ }^{10}$ Division of Endocrinology, Department of Medicine, Helsinki University Central Hospital, FIN-00029 Helsinki, Finland \\ (Correspondence should be addressed to O Vierimaa; Email: outi.vierimaa@oulu.fi)
}

\begin{abstract}
Objective: The existence of genotype-phenotype correlation in multiple endocrine neoplasia type 1 (MEN1) is controversial. Two founder mutations of the MEN1 gene in Northern Finland gave us an opportunity to compare clinical features among heterozygotes of different mutations.

Design and methods: Study cohort included 82 MEN1 heterozygotes who were tested for MEN1 during the years 1982-2001. Medical records were reviewed for manifestations of MEN1, other tumours and cause of death by the end of August 2003. Logistic regression analysis was used in evaluating the impact of age, gender and mutational status of affected heterozygotes on the likelihood of developing manifestations of MEN1.

Results: Founder mutations 1466del12 and 1657insC were found in 39 and 29 individuals, and D418N, G156R and R527X mutations in 9, 3 and 2 individuals respectively. Except for pituitary adenoma and nonfunctional pancreatic tumour (NFPT), age was a risk factor for all the disease manifestations. For NFPT, frameshift/nonsense mutations (1657insC, R527X) gave an odds ratio (OR) of 3.26 (95\% confidence intervals $(\mathrm{CI}), 1.27-8.33 ; P=0.014)$ compared with in-frame/missense mutations (1466del12, D418N, G156R); including the founder mutation carriers $(n=68)$ only, the 1657insC mutation gave an OR of 3.56 (CI, 1.29-9.83; $P=0.015)$. For gastrinoma, in-fra$\mathrm{me} / \mathrm{missense}$ mutations predicted the risk with an OR of 6.77 (CI, 1.31-35.0; $P=0.022$ ), and in the founder mutations group the 1466del12 mutation gave an OR of 15.09 (CI, 1.73-131.9, $P=0.014$ ). Conclusions: In this study population, NFPT was more common in the frameshift/nonsense or 1657insC mutation carriers, whereas gastrinoma was more common in the in-frame/missense or 1466del12 mutation carriers.
\end{abstract}

European Journal of Endocrinology 157 285-294

\section{Introduction}

Multiple endocrine neoplasia type 1 (MEN1, MIM $131100)$ is an autosomal dominantly inherited syndrome predisposing to parathyroid, neuroendocrine gastroenteropancreatic (GEP) and anterior pituitary tumours. The most frequent manifestation of MEN1 is primary hyperparathyroidism (PHPT) occurring in $82-95 \%$ of patients, while enteropancreatic tumours and anterior pituitary adenomas are found in $27-75 \%$ and $19-65 \%$ respectively (1-6). Adrenal lesions are seen in $5-40 \%(1,2,6,7)$ and neuroendocrine tumours of the gastrointestinal tract, bronchus or thymus in $4-9 \%$ of patients $(1,2,6)$. Leiomyoma of various sites and angiofibroma, collagenoma and lipoma of the skin are also seen in association with MEN1 $(8,9)$.
The gene for (MEN1) was characterised in 1997 $(10,11)$. MEN1 is a tumour suppressor gene that encodes a $67 \mathrm{kDa}$ protein of 610 amino acids, named menin, which is found mostly in the nucleus. Menin interacts with several other proteins such as JunD, Smad family members, NF- $\mathrm{B}$, vimentin and HSP70, and seems to function as a general regulator of transcription (12-14). Loss of its function through Knudson's two-hit model is an important step that can lead to various tumours seen in this syndrome (15).

To date, about 300 different MEN1 mutations have been reported (16). They are scattered throughout the entire MEN1 coding sequence. Most mutations described have been truncating mutations, thus supporting the function of menin as a tumour suppressor. Some mutational hot spots have been 
reported several times in the literature (16). Notably, an intron 4 mutation has been encountered in several unrelated families with considerable variation of tumour presentation (17). Some of the recurrent mutations are due to a founder effect, which has been reported, e.g. from Tasmania, Newfoundland and Northern Finland (18-20). In Northern Finland, two different founder mutations (1466del12 and 1657insC) have been found. Both these are located in exon 10 (20). Most reports doubt the existence of any kind of genotype-phenotype correlation in MEN1 syndrome implying that the underlying mutation would not predict the clinical picture. Neither the location of the mutation along the gene nor the mutation type (nonsense, missense, in-frame or frameshift deletion or insertion, splice-site defects) seems to have any effect upon the phenotype (21-24). In previous reports, however, the number of patients carrying the same mutation has usually been small, and this has made phenotype-genotype correlation analysis difficult.

Hitherto, only four studies reporting an apparent founder effect and several affected individuals carrying the same mutation have been reported. The best known of these has been described from Newfoundland and is called the 'Burin (Newfoundland)' or prolactinoma variant, where there is an exceptionally high prevalence of prolactinoma and a low prevalence of gastrinoma (19). All 83 patients belonging to 4 different families without a known common ancestor but sharing the same haplotype carried the same R460X (Arg 460Stop) mutation (19). Later, however, this same phenotype has been found to cosegregate even with other mutations (4). In addition, 64 patients from Tasmania carrying the same IVS2-3 (C-G) mutation have been reported (18). The founder effect has also been reported for mutation 512 delC (five out of six families originating from the Pennsylvania-Ohio region) and for 416delC (five kindreds also from the USA) (25). Thus, at present, it is unclear whether the prolactinoma variant is due to a genotype-phenotype effect or due to factors not related to the MEN1 gene.

In Finland, two different founder mutations (1466del12 and 1657insC) have been found (20). Today, more than 100 MEN1 patients with proven mutations are known. A majority of them carry either of the two founder mutations. This enrichment offers a good opportunity to study genotype-phenotype correlations in MEN1. The purpose of our study was to describe the clinical features of Northern Finnish MEN1 patients found during the years 1982-2001 and to evaluate the likelihood of genotypephenotype correlation among these patients.

\section{Subjects and methods}

The study population consists of 82 MEN1 mutation carriers belonging to 16 families found in the district of Oulu University Hospital during the years 1982-2001.
Initially, 25 index patients received genetic counselling at the Department of Clinical Genetics, Oulu University Hospital, which is responsible for genetic counselling in Northern Finland. Genetic counselling was also offered to their relatives at risk. After genetic counselling, a total of 159 subjects optioned for further studies. Prior to 1997, the ascertainment of heterozygotes was based on both biochemical and radiological information combined later with MEN1 linkage analysis. All these cases were confirmed by direct mutation analysis when it became possible in 1997. From then onwards all the new cases have been directly analysed by MEN1 mutation detecting.

Among the 159 individuals studied, the MEN1 gene analysis revealed 87 heterozygotes including 25 index patients and 62 newly diagnosed family members. Of the 62 newly diagnosed heterozygotes, five were excluded from the analysis for various reasons (Two were tested as newborns, two did not enter the screening programme and one was living outside Finland) and thus the remaining 82 individuals were included in the followup study. Altogether 72 subjects appeared to be noncarriers and could be excluded from the follow-ups.

All patients had regular follow-ups at the closest endocrinology unit for screening of the MEN1-related manifestations. The basic follow-up visit every 1 to 3 years consisted of biochemical screening of serum sample (ionized calcium, parathyroid hormone, pancreatic polypeptide (PP), gastrin, chromogranin A (CGA) and prolactin) and radiological imaging (ultrasound/computed tomography/magnetic resonance imaging) of the abdomen, pituitary and parathyroid glands. In cases of active disease, the patients were seen more frequently and a wide range of different diagnostic methods were used, including somatostatin-receptor scintigraphy to detect neuroendocrine tumours at various regions.

The medical records of the MEN1 heterozygotes were reviewed for the presence and timing of the MEN1related manifestations, possible other tumours and deaths. The onset and diagnosis of PHPT was defined as the first incidence of hypercalcaemia with an inappropriately elevated serum PTH level. The classification of GEP tumours was based on clinical evidence of excess hormone secretion or lack thereof, and in operated patients was confirmed by histology using the WHO criteria. For nonfunctional pancreatic tumours (NFPT), the diagnosis was based on either constantly elevated tumour markers (S-PP and/or S-CGA) or visualization of the tumours by imaging examinations in the absence of other pancreatic hormone oversecretion and clinical endocrine syndrome. The diagnosis of gastrinoma was based on elevated serum gastrin levels, confirmed in most cases with inappropriate rise during secretin test and/or increased gastric acid output. Pituitary adenomas were also classified according to the presence of hormonal activity or lack thereof on clinical and biochemical bases. They were considered 
as microadenomas less than when $10 \mathrm{~mm}$ and as macroadenomas when equal to or greater than $10 \mathrm{~mm}$ in diameter (26). Adrenal glands were regarded as affected when evidence of hyperplasia or tumours was seen in imaging studies and as hormonally active if so evidenced by biochemical testing of autonomous function in cortisol and aldosterone secretions. In addition to the medical records, the death certificates and the autopsy reports were studied, if available, for evaluating the causes of death.

The follow-up time was counted from the first visit to a health care institution for MEN1 suspicion in the patient or family. The last point of the observation period was counted as the last information concerning MEN1-associated documentation available by the end of August 2003 or patient's death by that time.

SPSS 12.0.1 (SPSS Inc., Chicago, IL, USA) was used for statistical analyses. Mean ages were reported as mean \pm 1 s.D. Binary logistic regression analysis was used for analysing the covariates affecting the likelihood of having different MEN1 manifestations. The study cohort was analysed in two groups containing either all the ascertained heterozygotes or just the founder mutation carriers. Covariates included in all of the analyses were age at the end of the follow-up, gender and mutational background (mutation class when analysing all the cases, and the exact mutation when analysing the founder mutation carriers). Confidence intervals $(\mathrm{CI})$ of $95 \%$ are reported in parenthesis after odds ratio $(\mathrm{OR})$ values. $P<0.05$ was considered significant. Penetrance of the major manifestations by age was calculated by Kaplan-Meier analysis.

The study has been accepted by the ethical committee of Oulu University Hospital. All patients and their relatives included in this study received genetic counselling and gave an informed consent for DNA studies.

\section{Results}

Of the 82 individuals ( 35 men, 47 women) found to be MEN1 heterozygous carriers, 68 (83\%) were found to carry either the mutation 1466 del12 or 1657 insC, which are the founder mutations in Northern Finland as described earlier (20). The mutation 1466del112 was found in 39 individuals belonging to 9 families, and 1657 insC was found in 29 individuals from 4 families. Three additional mutations D418N, G156R and R527X were found in 9, 3 and 2 individuals, respectively, belonging to 3 different families (Table 1). In-frame/ missense mutations (1466del12, D418N, G156R) were carried by 51 individuals and frameshift/nonsense mutations (1657insC, R527X) were carried by 31 individuals.

For the 82 mutation-positive individuals, the mean age at the onset of the follow-up was $40.8 \pm 14.6$ years (range 11-70 years) and the mean age at the end of the observation period was $48.1 \pm 15.4$ years (range $18-78$ years). The mean duration of the follow-up time was $7.3 \pm 4.5$ years (range $0-18$ years). Prevalence of different MEN1 manifestations in the 82 MEN1 heterozygotes is shown in Table 2 and age-dependent penetrance of the major manifestations according to Kaplan-Meier analysis in Fig. 1. The results of logistic regression analysis are briefed in Table 3. The major clinical and biochemical manifestations of MEN1 in these mutation-positive individuals were as follows:

\section{PHPT}

PHPT was detected in 31 males and 45 females $(n=76$; $93 \%$ ) at a mean age of $39.8 \pm 13.5$ years (range $16-69$ years; Table 2). Only six patients (7\%) remained normocalcaemic during the follow-up. For these six patients without PHPT, the mean age at the end of the observation period was $33.7 \pm 13.6$ years (range $18-54$ years).

A total of 43 patients $(52 \%)$ were operated on the parathyroid glands at least once. All of the removed glands showed benign histology except for one patient (patient 4-13), who was found to have metastasized parathyroid carcinoma affecting two glands at the age of 38 years.

In the statistical analysis of the 82 individuals, age appeared to be the only factor that could predict the likelihood of having PHPT, with an OR of 1.08 per year (95\% CI, 1.01-1.17; $P=0.031)$. Gender or mutation class did not have any effect. When analysing the carriers of the two founder mutations separately, none

Table 1 Mutations found in the 82 multiple endocrine neoplasia type 1 heterozygotes. For each mutation group the mean age of the heterozygotes at the beginning and at the end of the study is shown.

\begin{tabular}{lcccc}
\hline & & & Mean age \pm s.D. (years) \\
\cline { 3 - 5 } Mutation & $\begin{array}{c}\text { Class and location of } \\
\text { mutation }\end{array}$ & $\begin{array}{c}\text { Number (\%) of mutation } \\
\text { carriers }\end{array}$ & At beginning & At end \\
\hline 1466del12 & In-frame, exon 10 & $39(48 \%)$ & $44.6 \pm 14.4$ & $51.3 \pm 15.3$ \\
1657 insC & Frameshift, exon 10 & $29(35 \%)$ & $37.7 \pm 12.5$ & $45.2 \pm 13.8$ \\
D418N & Missense, exon 9 & $9(11 \%)$ & $37.9 \pm 19.4$ & $45.4 \pm 19.4$ \\
G156R & Missense, exon 3 & $3(4 \%)$ & $28.9 \pm 16.5$ & $37.0 \pm 17.8$ \\
R527X & Nonsense, exon 10 & $2(2 \%)$ & $41.8 \pm 1.9$ & $58.0 \pm 2.1$ \\
\hline
\end{tabular}


Table 2 Prevalences of the major multiple endocrine neoplasia type 1 (MEN1) manifestations among the 82 MEN1 heterozygotes in relation to the different mutations found.

\begin{tabular}{|c|c|c|c|c|c|c|}
\hline Tumour & 1466del12 & 1657insC & D418N & G156R & R527X & Total \\
\hline PHPT & 37 (95\%) & 26 (90\%) & $8(89 \%)$ & $3(100 \%)$ & $2(100 \%)$ & 76 (93\%) \\
\hline GEP (all) & $29(74 \%)$ & $21(72 \%)$ & $6(67 \%)$ & $2(67 \%)$ & $2(100 \%)$ & $60(73 \%)$ \\
\hline NFPT & $15(39 \%)$ & $20(69 \%)$ & $4(44 \%)$ & $1(33 \%)$ & $1(50 \%)$ & $41(50 \%)$ \\
\hline GASTR & 15 (39\%) & 1 (3\%) & 2 (22\%) & - & $1(50 \%)$ & $19(23 \%)$ \\
\hline Other & - & $1(3 \%)$ & - & $1(33 \%)$ & - & $2(2 \%)$ \\
\hline NEGT & 2 (5\%) & $2(7 \%)$ & $1(11 \%)$ & - & - & $5(6 \%)$ \\
\hline PIT (all) & $10(26 \%)$ & $9(31 \%)$ & $2(22 \%)$ & $2(67 \%)$ & $1(50 \%)$ & $24(29 \%)$ \\
\hline PROL & 7 (18\%) & $6(21 \%)$ & 2 (22\%) & $2(67 \%)$ & - & $17(21 \%)$ \\
\hline NFPIT & 3 (8\%) & $2(7 \%)$ & - & - & $1(50 \%)$ & $6(7 \%)$ \\
\hline Mixed & _ & $1(3 \%)^{a}$ & - & - & - & $1(1 \%)$ \\
\hline THYM & - & $2(7 \%)$ & - & - & $1(50 \%)$ & $3(4 \%)$ \\
\hline ADR & $15(39 \%)$ & 7 (24\%) & $4(44 \%)$ & $1(33 \%)$ & $2(100 \%)$ & $29(35 \%)$ \\
\hline
\end{tabular}

PHPT, primary hyperparathyroidism is considered as a sign of parathyroid tumour (hyperplasia or adenoma); GEP, gastroenteropancreatic tumour; NFPT, nonfunctional pancreatic tumour; GASTR, gastrinoma, other GEP, insulinoma (1657insC), growth hormone-releasing-hormone secreting tumour GHRHoma (G156R); NEGT, neuroendocrine tumour (carcinoid) of gastrointestinal tract; PIT, pituitary adenoma; PROL, prolactinoma; NFPIT, nonfunctional pituitary adenoma, THYM, neuroendocrine carcinoma of thymus; ADR, adrenal lesions.

${ }^{a}$ Mixed adenoma in this patient - secreted both prolactin and TSH.

of the covariates (age, gender or mutation) could predict the risk for PHPT.

\section{Neuroendocrine GEP tumours (GEP)}

In this patient cohort, four types of GEP tumours could be found; NFPTs, gastrinomas, other hormonally active pancreatic tumours and neuroendocrine tumours of gastrointestinal tract, formerly termed carcinoids. Mean age at the end of the follow-up for the patients not having any signs of GEP tumours was
$34.0 \pm 12.4$ years (range 18-65 years). GEP tumours were found in 26 males and 34 females $(n=60$ or $73 \%$ ) at a mean age of $46.8 \pm 12.8$ years (range 21-69 years). Metastasized GEP tumours were present in 13 patients $(16 \%)$, eight males and five females, at a mean age of $55.1 \pm 12.4$ years (range 28-70 years). Of the patients with GEP tumours, $18(30 \%)$ had undergone an operation to remove or reduce the size of the tumour. In the statistical analysis of all the 82 subjects, only age at the end of the observation period (OR, 1.12; CI, 1.06-1.19; $P=0.000$ ) was found to be a risk factor for GEP tumours. Gender or mutation

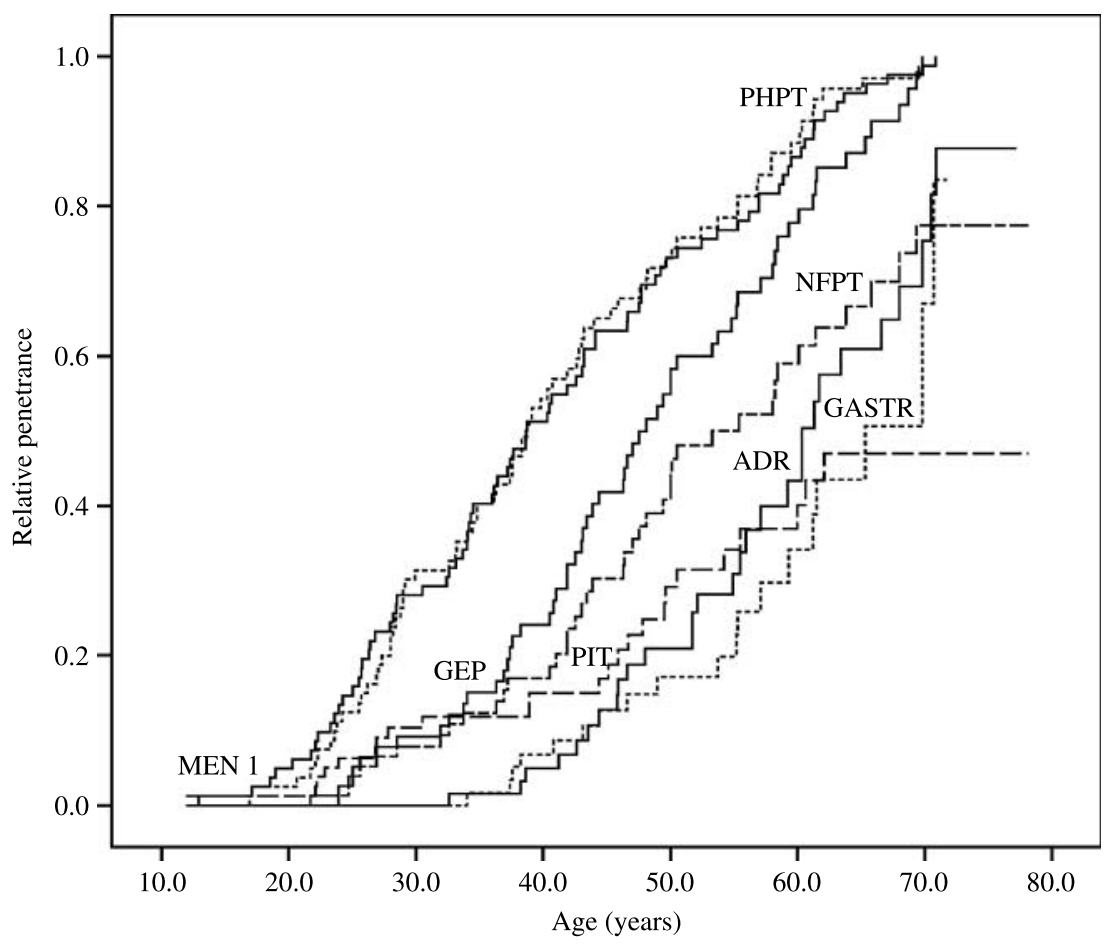

Figure 1 Cumulative penetrance by Kaplan-Meier analysis of multiple endocrine neoplasia type 1 (MEN1), primary hyperparathyroidism (PHPT), gastroenteropancreatic tumour (GEP), gastrinoma (GASTR), nonfunctional pancreatic tumour (NFPT), adrenal lesion (ADR) and pituitary adenoma (PIT) in relation to the age of the 82 MEN1 mutation carriers. 
Table 3 Risk factors for different multiple endocrine neoplasia type 1 (MEN1) manifestations found through logistic regression analysis including age, gender and mutational status as covariates in the group of 82 MEN1 mutation carriers (top) and in the group of 68 MEN1 founder mutation carriers (below); OR, odds ratio; $\mathrm{Cl}$, confidence intervals of $95 \%$.

\begin{tabular}{|c|c|c|c|}
\hline Covariate & OR & Cl & $\boldsymbol{P}$ \\
\hline \multicolumn{4}{|l|}{ Age } \\
\hline PHPT & 1.08 & $1.01-1.17$ & 0.031 \\
\hline GEP (all) & 1.12 & $1.06-1.19$ & 0.000 \\
\hline Gastrinoma & 1.09 & $1.04-1.15$ & 0.001 \\
\hline Metastasized GEP & 1.07 & $1.02-1.12$ & 0.008 \\
\hline ADR & 1.09 & $1.05-1.14$ & 0.000 \\
\hline Gender & \multicolumn{3}{|c|}{ Not found to be a risk factor } \\
\hline \multicolumn{4}{|c|}{ In-frame deletion/missense mutation } \\
\hline Gastrinoma & 6.77 & $1.31-35.0$ & 0.022 \\
\hline \multicolumn{4}{|c|}{ Frameshift insertion/nonsense mutation } \\
\hline NFPT & 3.26 & $1.27-8.33$ & 0.014 \\
\hline \multicolumn{4}{|l|}{ Age } \\
\hline GEP (all) & 1.11 & $1.05-1.17$ & 0.000 \\
\hline Gastrinoma & 1.08 & $1.03-1.14$ & 0.004 \\
\hline Metastasized GEP & 1.08 & $1.03-1.15$ & 0.005 \\
\hline ADR & 1.09 & $1.04-1.14$ & 0.000 \\
\hline \multicolumn{4}{|c|}{ Gender (male) } \\
\hline Metastasized GEP & 4.27 & $1.03-17.6$ & 0.045 \\
\hline \multicolumn{4}{|c|}{ 1466del12 mutation } \\
\hline \multicolumn{4}{|c|}{ 1657insC mutation } \\
\hline NFPT & 3.56 & $1.29-9.83$ & 0.015 \\
\hline
\end{tabular}

PHPT, primary hyperparathyroidism; GEP, gastroenteropancreatic tumour NFPT, nonfunctional pancreatic tumour, gastrinoma, metastasized GEP pituitary adenoma, prolactinoma, nonfunctional pituitary adenoma; ADR adrenal lesions.

status had no effect. The result was similar in the subgroup of the founder mutations carriers, with age being the only significant risk factor (OR, 1.11; CI, $1.05-1.17 ; P=0.000$ ).

The most prevalent type of GEP tumour was a NFPT present in 17 males and 24 females $(n=41$ or $50 \%)$ at a mean age of $45.3 \pm 12.5$ years (range 23-69 years). Of these, $20(49 \%)$ had the 1657insC, $15(37 \%)$ the $1466 \mathrm{del} 12,4(10 \%)$ the D418N and $1(2 \%)$ the R $527 \mathrm{X}$ and G156R mutations. The risk for NFPT could not be predicted by age or gender, but the mutation class including the frameshift and nonsense mutations gave an OR of 3.26 (CI, 1.27-8.33; $P=0.014$ ) compared with the other mutation class with in-frame and missense changes in the group of 82 subjects. Among the two founder mutations, $1657 \mathrm{insC}$ appeared to be a risk factor for NFPTs with an OR of 3.56 (CI, 1.29-9.83, $P=0.015$ ).

Gastrinomas were suspected clinically and biochemically in 8 males and 11 females $(n=19$ or $23 \%)$ at a mean age of $51.6 \pm 11.4$ years (range 34-70 years). Of these patients, 15 (79\%) had the 1466 del 12 founder mutation. Two other patients (11\%) had the $\mathrm{D} 418 \mathrm{~N}$ mutation, one patient $(5 \%)$ the 1657 insC founder mutation and another one $(5 \%)$ the R $527 \mathrm{X}$ mutation. Gastrinoma patients were found in seven out of nine $(78 \%)$ of the families carrying the 1466 del12 mutation. For the whole material, risk factors for gastrinoma were age (OR, 1.09; CI, 1.04-1.15; $P=0.001)$ and mutation class including in-frame and missense changes (OR, 6.77; CI, 1.31-35.0; $P=0.022$ ). In the founder mutations group, the 1466del12 mutation was strongly associated with gastrinoma and gave an OR of 15.1 (CI, 1.73-131.9; $P=0.014$ ) compared to the 1657insC mutation; age gave an OR of 1.08 (CI, 1.03-1.14; $P=0.004)$.

An insulinoma was found in one female patient (age 31 years), and a pancreatic growth hormone-releasing hormone secreting tumour resulting in acromegaly was seen in one male patient (age 21 years). Neuroendocrine tumours of the gastrointestinal tract (other than duodenal gastrinomas) were found in five female patients with a mean age of $55.4 \pm 9.9$ years (range 44-68 years), associating with hypergastrinemia in three of them. All of these five patients were also affected by pancreatic endocrine lesions.

All the patients with metastasized GEP tumours had either the 1466del12 (nine cases) or the 1657insC (four cases) mutation. Lymph node metastases were found in three males and three females, and liver metastases were found in five males and two females. The risk for metastases was increased by advancing age in both settings ( 82 vs 68 patients), with an OR of 1.07 (CI, 1.02-1.12, $P=0.008)$ and 1.08 (CI, 1.03-1.15, $P=0.005)$ respectively. In addition, in the founder mutations group, male gender gave an OR of 4.27 (CI, 1.03-17.6; $P=0.045$ ).

\section{Pituitary tumours}

Pituitary adenomas were found in 24 patients (29\%), 7 males, 17 females, at a mean age of $40.2 \pm 14.4$ years (range 12-62 years). Mean age for those without a tumour was $47.5 \pm 16.0$ years (range $18-78$ years) at the end of the follow-up. Among the patients with pituitary adenomas, $17(71 \%)$ had prolactinoma, 6 (25\%) had a nonfunctional tumour and 1 had a mixed adenoma secreting both prolactin and TSH. Upon imaging, $12(50 \%)$ were classified as macroadenomas and $11(46 \%)$ were microadenomas. One prolactinoma could not be visualized. Of the patients with pituitary adenomas, $12(50 \%)$ had received some therapy. Dopamine agonist treatment had been given to 10 (42\%), and 5 had also been operated. Another patient with prolactinoma received only operative treatment, and one further patient with a nonfunctional adenoma had received radiation therapy.

In addition to the patients with adenomas, there was one further patient (patient 4-13) with sellar tumour diagnosed at 9 years of age. According to the histology report, the removed tumour was angiosarcoma. The tumour sample was not available for review. The patient received radiation therapy and was followed-up by endocrinologist for panhypopituitarism. At 37 years of age, he was found to be a MEN1 heterozygote through family screening. Two years after entering the followup, he died of metastasized parathyroid cancer. 
The risk of pituitary adenoma or prolactinoma was not predicted by age, gender or mutational background in either of the settings.

\section{Other neuroendocrine tumours}

Neuroendocrine tumours beyond the gastrointestinal tract were all thymic in origin (thymic carcinoids or neuroendocrine carcinoma of thymus) and were found in three male patients. The patients were two brothers with the 1657 insC mutation at ages 45 and 52 years and another male patient with the R527X mutation at 55 years of age. By the end of the follow-up, the brothers had developed local recurrences at 47 and 55 years of age, and the former was also found to have skeletal metastases in the spine before his death (patient 12-8). The third patient did not show any signs of thymic neuroendocrine carcinoma six months after the operation.

\section{Adrenal lesions}

Adrenal lesions were present in 29 (35\%) of the patients (12 males, 17 females) at a mean age of $53.7 \pm 10.6$ years (range, 32-70 years). All the lesions were considered benign and hormonally inactive, except for two patients, who had subclinical hypercortisolism. Of the patients with adrenal lesions, 28 (97\%) were also affected by one or more GEP tumours including 15 with NFPTs (52\%), 12 with gastrinomas $(41 \%)$ and 1 with both $(3 \%)$.

Age was the only variable that could predict the likelihood of having adrenal lesions with an OR of 1.09 (CI, 1.05-1.14; $P=0.000$ ) in the group of all the patients, and similarly 1.09 (CI, 1.04-1.14; $P=0.000$ ) in the founder mutations group.

\section{Other tumours}

Other tumours found in the study population are shown in Table 4. Systematic search for cutaneous tumours or uterine leiomyomas was not performed.

\section{Deaths}

During the observation period, nine men and six women died at a mean age of $59.0 \pm 12.7$ years (range 39-72 years) and 62.9 \pm 15.0 years (range 36-79 years) respectively (Table 5). MEN1 was considered to be a direct cause of death in seven cases - a metastasized GEP tumour in five patients and a parathyroid carcinoma in one patient. In addition, for one patient diagnosed with gastrinoma 15 years earlier, the cause of death was haemorrhage from a duodenal ulcer. He had refused to go to the follow-up visits 8 years earlier. MEN1 was a contributing factor of death in three cases, presenting as a metastasized pancreatic neuroendocrine tumour in two patients and as a thymic neuroendocrine carcinoma in one patient. Five patients died of nonMEN1-related causes (Table 5).

\section{Discussion}

Well described in the literature more than 100 years ago (27), MEN1 still appears a challenge for genetic counsellors and clinicians regarding the prognosis, follow-up and clinical manifestations. Molecular diagnostic methods have greatly improved the diagnosis of MEN1, but lack of knowledge about the genotype-phenotype correlation as well as inconsistent opinions regarding the risk of developing various tumours is problematic, especially when doing predictive genetic testing.

Two founder mutations common in Northern Finland and resulting in a cluster of MEN1 patients (20), as well as a well-organized health care system, offer a good opportunity to study this disease with unbiased material on a population basis. In the present study, we found 15 patients $(38 \%)$ with gastrinoma among 39 individuals carrying the 1466 del 12 mutation, and only 1 patient (3\%) with gastrinoma among 29 individuals carrying the 1657insC mutation. This seems to indicate that the 1466del12 carrier patients are more prone to developing gastrinomas. On the other hand, the prevalence of NFPTs among the 1466del12 mutation carriers was significantly lower, $15(38 \%)$ vs 20 (69\%), when compared to 1657 insC mutation carriers. Resembling our findings, enteropancreatic lesions showed intrafamilial homogeneity in a 10-year prospective screening study published from Sweden (5). In their study, insulin-proinsulin excess was significantly overrepresented in a family with a pronounced malignant profile of their pancreatic tumours, whereas in another family all pancreatic lesions were benign and only the Zollinger-Ellison syndrome was displayed. Contrary to the study by Skogseid et al. (5), we could not find any differences between families according to the malignant behaviour of GEP tumours. Instead, male gender seemed to be a risk factor for developing metastasising GEP tumours.

The 1466del12 mutation, located in exon 10, is an in-frame deletion that is predicted to shorten the menin protein by four amino acids at codons $453-456$. The deleted region locates in the area that is required for interaction with PEM and NM23H1 proteins (12). The frameshift mutation 1657 insC at codon 516 is predicted to cause a premature stop codon, 14 codons upstream (17). This affects the binding site with Smad3 and cuts the nuclear localization signal-2 off (12). It is not known whether these changes in interaction due to MEN1 mutations have any role in the tumourigenesis of gastrinomas or NFPTs.

Hao et al. described two kindreds (A and B) with low prevalence of gastrinoma $(10 \%)$ and high prevalence of prolactinoma $(40 \%)(4)$. The authors pointed out that the difference in typical MEN1 was more striking for 
Table 4 Other than classical multiple endocrine neoplasia type 1 (MEN 1) tumours among the 82 MEN1 heterozygotes. Patients 4-3 and 4-4 are sisters. Patients 14-12, 14-14 and 14-28 are siblings, and patient 14-54 is a daughter of one of their sisters. Patient 11-6 is an aunt to patient 11-21.

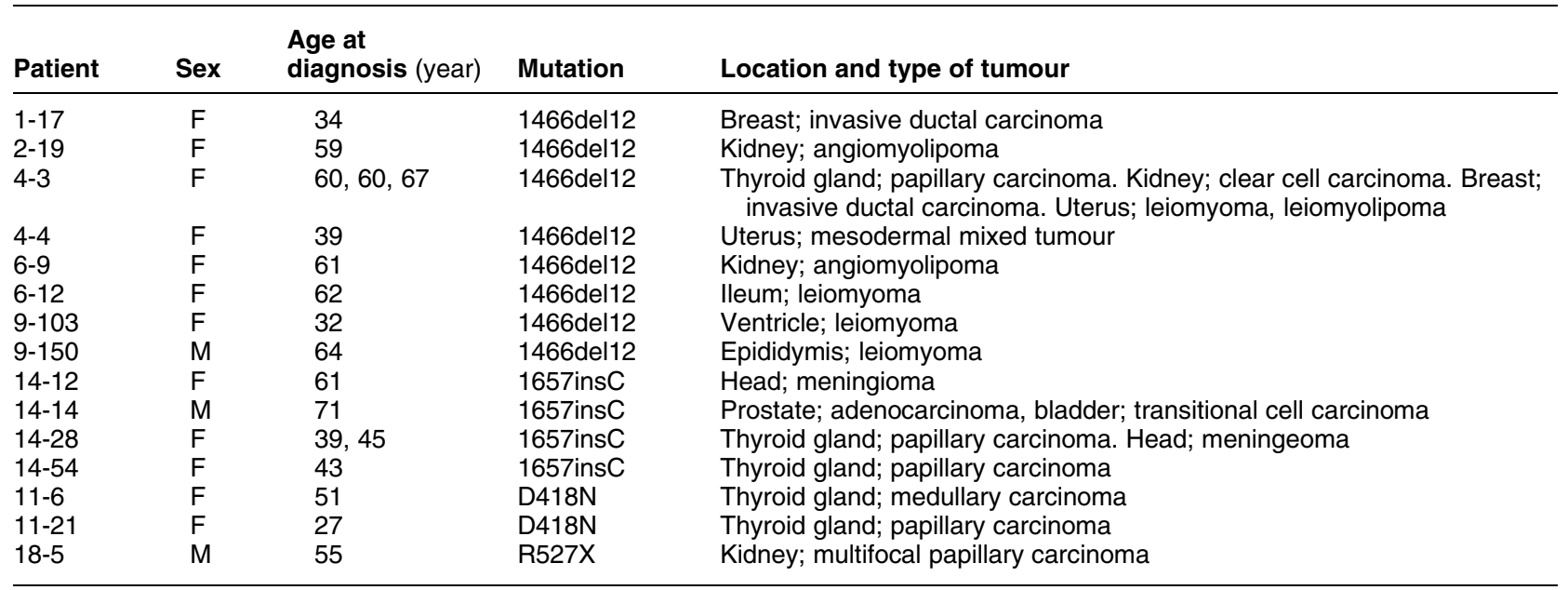

gastrinoma than for prolactinoma. Patients from kindred B harboured a nonsense mutation Y312X, while no MEN1 mutation was identified in kindred A. Patients with a prolactinoma variant from Newfoundland had a nonsense mutation R460X. A common finding between cases with a prolactinoma variant and 1657insC mutation carriers is a low prevalence of gastrinoma. Also, all three mutations lead to truncated proteins, like most of the MEN1 mutations (12). In the present study, the mutation class leading to truncated proteins (frameshift insertion/nonsense mutation) was found to be a risk factor for NFPT, while mutation class leading to presumably lesser changes in the menin protein (in-frame deletion/missense mutations) predicted a risk for gastrinomas. In a paper on genotype-phenotype correlation of MEN1 mutations in sporadic gastrinomas (28), authors combined their data with results taken from other cases of sporadic gastrinomas (29). They stated that $40 \%$ (11 out of 28 ) of mutations described (eight missense and three in-frame deletions) altered the amino acid sequence of menin, while $60 \%$ (17 out of 28 ) resulted in a truncated protein. In familial MEN1, the majority $(73 \%)$ of the mutations lead to a truncated protein $(21-23)$.

In the present study, the likelihood of having a GEP tumour was increased with advancing age, with an OR of 1.12 in the entire group and 1.11 in the subgroup of the founder mutation carriers. According to Kaplan-Meier analysis, the penetrance of GEP tumours is $100 \%$ by 70 years of age (Fig. 1). Similar to the findings in a

Table 5 Cause of death of the 15 multiple endocrine neoplasia type 1 (MEN1) heterozygotes who died during the follow-up. Contributing factors of death are shown in parentheses.

\begin{tabular}{|c|c|c|c|c|}
\hline Patient & Sex & $\begin{array}{l}\text { Age at } \\
\text { death (years) }\end{array}$ & Mutation & Cause of death (*if unrelated to MEN1) \\
\hline $1-3$ & $\mathrm{~F}$ & 70 & 1466del12 & Pancreatic gastrinoma with liver metastases \\
\hline $1-7$ & M & 70 & 1466del12 & Bleeding duodenal ulcer due to gastrinoma \\
\hline $1-12$ & M & 52 & 1466del12 & Mesenteric artery thrombosis ${ }^{\star}$ \\
\hline $1-17$ & $\mathrm{~F}$ & 36 & 1466del12 & Breast cancer with metastases* \\
\hline 2-19 & $\mathrm{F}$ & 62 & 1466del12 & $\begin{array}{l}\text { Cor pulmonale* (nonfunctional pancreatic tumour with local lymph node } \\
\text { metastases) }\end{array}$ \\
\hline 3-31 & M & 44 & 1466del12 & Suicide* $^{*}$ \\
\hline $4-13$ & M & 39 & 1466del12 & Parathyroid carcinoma with multiple metastases \\
\hline 7-4 & M & 72 & 1466del12 & Pancreatic gastrinoma with liver metastases \\
\hline $9-159$ & M & 59 & 1466del12 & Nonfunctional pancreatic tumour with liver metastases \\
\hline $11-6$ & $\mathrm{~F}$ & 79 & $\mathrm{D} 418 \mathrm{~N}$ & Acute myocardial infarction* (diabetes) \\
\hline $12-8$ & M & 51 & 1657insC & $\begin{array}{l}\text { Cardiac insufficiency due to chronic pericarditis* (neuroendocrine carcinoma } \\
\text { of the thymus) }\end{array}$ \\
\hline 14-12 & $\mathrm{F}$ & 70 & 1657insC & Nonfunctional pancreatic tumour with local lymph node metastases \\
\hline $14-14$ & M & 72 & 1657 ins C & Pulmonary artery embolism after cholecystectomy for a necrotic cholecystitis* \\
\hline 14-18 & M & 68 & 1657insC & Lewy body dementia* (non-functional pancreatic tumour with liver metastases) \\
\hline $14-23$ & $\mathrm{~F}$ & 57 & 1657insC & $\begin{array}{l}\text { Neuroendocrine carcinoma of the stomach and the duodenum with multiple } \\
\text { metastases }\end{array}$ \\
\hline
\end{tabular}


Tasmanian kindred study (2), however, when NFPTs were analysed alone they were not associated with advancing age.

Our findings of age-related penetrance of other various MEN1 lesions are in agreement with previous studies $(2,4,5,30)$. In the present study, the peak of the prevalence of pituitary tumours is reached at around 60 years of age (Fig. 1), and age was not found to be a risk factor for pituitary tumours. A similar finding with prolactinoma was also seen in the Tasmanian kindred study (2). Also in our study, mutational background or gender did not predict the risk for pituitary adenoma or prolactinoma. In a large multicentre study, Vergès et al. (6) found that $85 \%$ of the tumours were macroadenomas, whereas in our study the proportion of macroadenomas was $50 \%$. This difference may reflect the higher proportion of newly diagnosed heterozygotes with early diagnoses in our study. Also, in the study of Vergès et al. (6), there were tumours secreting growth hormone $(\mathrm{GH})$ or adrenocorticotrophin in 4 and $2 \%$ respectively, and cosecreting and nonsecreting tumours in 4 and $6 \%$ respectively. The almost total lack of functioning pituitary adenomas other than prolactinomas in our study may be due to the overall lower number of pituitary tumours as compared with the number of pituitary adenomas $(n=136)$ in the large multicentre study (6). Nevertheless, the lack of GH-secreting adenomas has also been shown in the Tasmanian kindred where 124 patients were reviewed (32).

The only identifiable risk factor for developing PHPT was advancing age, with an OR of 1.08 per year. According to Kaplan-Meier analysis, the penetrance of PHPT would be $100 \%$ by 70 years of age (Fig. 1). One patient (Table 5, patient 4-13) was found to have multiglandular parathyroid cancer, which is extremely rare either as a sporadic form or associated with MEN1. It is not known whether the past radiation therapy on presumed sellar angiosarcoma or peculiar family history of different cancers (Table 4; patient 4-3 is the mother and 4-4 the mother's sister of patient 4-13) had any aetiological impact on the development of parathyroid cancer.

The prevalence of adrenal tumours (35\%) in this study is one of the highest reported in the literature $(1,2,6,7)$. This could be due to the high frequency of imaging studies we used. There are also reports including adrenal carcinoma in a varying amount of patients $(7,33)$. We could find only benign lesions, and only two were associated with subclinical hypercortisolism. Similarly, indolent courses of adrenal lesions has also been reported elsewhere $(32,35)$.

The occurrence of neuroendocrine gastrointestinal tumours (known earlier as carcinoids) only in women in the present study may be a coincidence. Nevertheless, in this study we noted thymic neuroendocrine tumours only in men in accordance with the previous reports $(36,37)$. Although we did not find any bronchial neuroendocrine tumours in our study, they are usually seen more frequently in women (38). Regarding these data, it is apparent that there exists some clinical variation in MEN1 according to the gender of the affected heterozygote.

There were five cases of thyroid cancer in this study. The aetiology of these and other tumours outside the classical MEN1 tumour spectrum (Table 4) noted in our study is not known. However, others had shown by loss of heterozygosity studies that leiomyomas of the oesophagus and uterus, meningioma and lipoma may be part of MEN1 syndrome $(8,9,39)$. It is also of note that medullary thyroid carcinoma (Table 4, patient 11-6) is a typical finding in patients with MEN2 and its occurrence in our patient with MEN1 is probably coincidence.

Of the deaths directly caused by MEN1, six (86\%) were caused by metastasized tumours associated with MEN1 and only one was caused by complications of peptic ulcer disease. This is in accordance with some recent studies $(30,40,41)$, whereas in older studies peptic ulcer disease was the most common MEN1-associated cause of death $(42,43)$. Owing to the small overall number of deaths in this study, no further analysis on mortality was undertaken. We have previously shown that MEN1 gene founder mutations did not cause harmful effect on survival in a historical cohort (44).

In conclusion, our study indicates that there is some variation in the risks for certain types of GEP tumours between patients with different MEN1 mutations. Whether this phenomenon is caused by mutation per se and subsequent variations of mutated menin products in different transcriptional interactions or some other factor, like a modifier gene cosegregating with MEN1 gene, needs further studying. Also, further study is needed before extending these findings from our northern Finnish families to other families carrying the same MEN1 gene mutations.

\section{Acknowledgements}

This work has been supported by Oulu University Hospital scientific programme and grants from the Cancer Society of Northern Finland and the National Graduate School of Clinical Investigation. The authors thank Mrs Outi Kajula and Mrs Riitta Mattlar for their valuable help in practical matters during this study.

\section{References}

1 Trump D, Farren B, Wooding C, Pang JT, Besser GM, Buchanan KD, Edwards CR, Heath DA, Jackson CE, Jansen S, Lips K, Monson JP, Halloran O', Sampson J, Shalet SM, Wheeler MH, Zink A \& Thakker RV. Clinical studies of multiple endocrine neoplasia type 1 (MEN1). Quarterly Journal of Medicine $199689653-669$. 
2 Burgess JR, Greenaway TM \& Shepherd JJ. Expression of the $M E N-1$ gene in large kindred with multiple endocrine neoplasia type 1. Journal of Internal Medicine 1998243 465-470.

3 Carty SE, Helm AK, Amico JA, Clarke MR, Foley TP, Watson CG \& Mulvihill JJ. The variable penetrance and spectrum of manifestations of multiple endocrine neoplasia type 1. Surgery 1998 124 1106-1113.

4 Hao W, Skarulis MC, Simonds WF, Weinstein LS, Agarwal SK, Mateo C, James-Newton L, Hobbs GR, Gibril F, Jensen RT \& Marx SJ. Multiple endocrine neoplasia type 1 variant with frequent prolactinoma and rare gastrinoma. Journal of Clinical Endocrinology and Metabolism $2004893776-3784$.

5 Skogseid B, Eriksson B, Lundqvist G, Lorelius LE, Rastad J, Wide L, Akerstrom G \& Oberg K. Multiple endocrine neoplasia type 1: a 10-year prospective screening study in four kindreds. Journal of Clinical Endocrinology and Metabolism 199173 281-287.

6 Verges B, Boureille F, Goudet P, Murat A, Beckers A, Sassolas G, Cougard P, Chambe B, Montyernay C \& Calender A. Pituitary disease in MEN type 1 (MEN1): data from the France-Belgium MEN1 multicenter study. Journal of Clinical Endocrinology and Metabolism 200287 457-465.

7 Skogseid B, Rastad J, Gobl A, Larsson C, Backlin K, Juhlin C, Akerstrom G \& Oberg K. Adrenal lesion in multiple endocrine neoplasia type 1. Surgery $1995 \mathbf{1 1 8} 1077-1082$.

8 Pack S, Turner ML, Zhuang Z, Vortmeyer AO, Boni R, Skarulis M, Marx SJ \& Darling TN. Cutaneous tumors in patients with multiple endocrine neoplasia type 1 show allelic deletion of the MEN1 gene. Journal of Investigative Dermatology $1998110438-440$.

9 McKeeby JL, Li X, Zhuang Z, Vortmeyer AO, Huang S, Pirner M, Skarulis MC, James-Newton L, Marx SJ \& Lubensky IA. Multiple leiomyomas of the esophagus, lung, and uterus in multiple endocrine neoplasia type 1. American Journal of Pathology 2001 $1591121-1127$.

10 Chandrasekharappa SC, Guru SC, Manickam P, Olufemi SE, Collins FS, Emmert-Buck MR, Debelenko LV, Zhuang Z, Lubensky IA, Liotta LA, Crabtree JS, Wang Y, Roe BA, Weisemann J, Boguski MS, Agarwal SK, Kester MB, Kim YS, Heppner C, Dong Q, Spiegel AM, Burns AL \& Marx SJ. Positional cloning of the gene for multiple endocrine neoplasia-type 1. Science $1997276404-407$.

11 Lemmens I, Van de Ven WJ, Kas K, Zhang CX, Giraud S, Wautout V, Buisson N, De Witte K, Salandre J, Lenoir G, Pugeat M, Calender A, Parente F, Quincey D, Gaudray P, De Wit MJ, Lips CJ, Hoppener JW, Khodaei S, Grant AL, Weber G, Kytola S, Teh BT, Farnebo F, Phelan C, Hayward N, Larsson C, Pannett AA, Forbes SA, Bassett JH \& Thakker RV. Identification of the multiple endocrine neoplasia type 1 (MEN1) gene. The European Consortium on MEN1. Human Molecular Genetics 1997 6 1177-1183.

12 Chandrasekharappa SC \& The BT. Functional studies of the MEN1 gene. Journal of Internal Medicine $2003253606-615$.

13 Poisson A, Zablewska B \& Gaudray P. Menin interacting proteins as clues toward the understanding of multiple endocrine neoplasia type 1. Cancer Letters 2003189 1-10.

14 Scacheri PC, Davis S, Odom DT, Crawford GE, Perkins S, Halawi MJ, Agarwal SK, Marx SJ, Spiegel AM, Meltzer PS \& Collins FS. Genome-wide analysis of menin binding provides insights into MEN1 tumorigenesis. PLoS Genetics 20062 e51.

15 Pannett AA \& Thakker RV. Somatic mutations in MEN type 1 tumors, consistent with the Knudson 'two-hit' hypothesis. Journal of Clinical Endocrinology and Metabolism $2001 \mathbf{8 6}$ 4371-4374.

16 Guo SS \& Sawicki MP. Molecular and genetic mechanisms of tumorigenesis in multiple endocrine neoplasia type-1. Molecular Endocrinology 200115 1653-1664.

17 Turner JJ, Leotlela PD, Pannett AA, Forbes SA, Bassett JH, Harding B, Christie PT, Bowen-Jones D, Ellard S, Hattersley A, Jackson CE, Pope R, Quarrell OW, Trembath R \& Thakker RV. Frequent occurrence of an intron 4 mutation in multiple endocrine neoplasia type 1. Journal of Clinical Endocrinology and Metabolism 200287 2688-2693.
18 Burgess JR, Nord B, David R, Greenaway TM, Parameswaran V, Larsson C, Shepherd JJ \& The BT. Phenotype and phenocopy: the relationship between genotype and clinical phenotype in a single large family with multiple endocrine neoplasia type 1 (MEN 1). Clinical Endocrinology 200053 205-211.

19 Olufemi SE, Green JS, Manickam P, Guru SC, Agarwal SK, Kester MB, Dong Q, Burns AL, Spiegel AM, Marx SJ, Collins FS \& Chandrasekharappa SC. Common ancestral mutation in the MEN1 gene is likely responsible for the prolactinoma variant of MEN1 (MEN1Burin) in four kindreds from Newfoundland. Human Mutation $199811264-269$.

20 Kytola S, Villablanca A, Ebeling T, Nord B, Larsson C, Hoog A, Wong FK, Valimaki M, Vierimaa O, The BT, Salmela PI \& Leisti J. Founder effect in multiple endocrine neoplasia type 1 (MEN 1) in Finland. Journal of Medical Genetics 200138 185-189.

21 Agarwal SK, Kester MB, Debelenko LV, Heppner C, EmmertBuck MR, Skarulis MC, Doppman JL, Kim YS, Lubensky IA, Zhuang Z, Green SJ, Guru SC, Manickam P, Olufemi SE, Liotta LA, Chandrasekharappa SC, Collins FS, Spiegel AM, Burns AL \& Marx SJ. Germline mutations of the MEN1 gene in familial multiple endocrine neoplasia type 1 and related states. Human Molecular Genetics $199761169-1175$.

22 Bassett JH, Forbes SA, Pannett AA, Lloyd SE, Christie PT, Wooding C, Harding B, Besser GM, Edwards CR, Monson JP, Sampson J, Wass JA, Wheeler MH \& Thakker RV. Characterization of mutations in patients with multiple endocrine neoplasia type 1 . American Journal of Human Genetics 199862 232-244.

23 Giraud S, Zhang CX, Serova-Sinilnikova O, Wautout V, Salandre J, Buisson N, Watrelot C, Bauters C, Porchet N, Aubert JP, Emy P, Cadiot G, Delemer B, Chabre O, Niccoli P, Leprat F, Duron F, Emperauger B, Cougart P, Goudet P, Sarfati E, Riou JP, Guichard S, Rodier M, Meyrier A, Caron P, Vantyghem MC, Assayag M, Peix JL, Pugeat M, Rohmer V, Vallotton M, Lenoir G, Gaudray P, Proye C, Conte-devolx B, Chanson P, Shugart YY, Goldgar D, Murat A \& Calender A. Germ-line mutation analysis in patients with multiple endocrine neoplasia type 1 and related disorders. American Journal of Human Genetics 199863 455-467.

24 Wautout V, Vercherat C, Lespinasse J, Chambe B, Lenoir GM, Zhang CX, Porchet N, Cordier M, Beroud C \& Calender A. Germline mutation profile of MEN1 in multiple endocrine neoplasia type 1: search for correlation between phenotype and the functional domains of the MEN1 protein. Human Mutation 200220 25-47.

25 Agarwal SK, Debelenko LV, Kester MB, Guru SC, Manickam P, Olufemi SE, Skarulis MC, Heppner C, Crabtree JS, Lubensky IA, Zhuang Z, Kim YS, Chandrasekharappa SC, Collins FS, Liotta LA, Spiegel AM, Burns AL, Emmert-Buck MR \& Marx SJ. Analysis of recurrent germline mutations in the MEN1 gene encountered in apparently unrelated families. Human Mutation 199812 75-82.

26 Hardy J. Transphenoidal surgery of hypersecreting pituitary tumors. In Diagnosis and Treatment of Pituitary Tumors, pp 179-194. EdsPO Kholer \& GT Ross, New York: Elsevier Publishing Co, Inc, 1973.

27 Erdheim J. Zur normalen und patologischen histologie der glandula thyroidea, parathyroidea, und hypophysis. Beitrage Zur Pathologischen Anatomie 190333158.

28 Goebel SU, Heppner C, Burns AL, Marx SJ, Spiegel AM, Zhuang Z, Lubensky IA, Gibril F, Jensen RT \& Serrano J. Genotype/phenotype correlation of multiple endocrine neoplasia type 1 gene mutations in sporadic gastrinomas. Journal of Clinical Endocrinology and Metabolism 200085 116-123.

29 Wang EH, Ebrahimi SA, Wu AY, Kashefi C, Passaro E, Jr \& Sawicki MP. Mutation of the MENIN gene in sporadic pancreatic endocrine tumors. Cancer Research 199858 4417-4420.

30 Geerdink EA, Van der Luijt RB \& Lips CJ. Do patients with multiple endocrine neoplasia syndrome type 1 benefit from periodical screening? European Journal of Endocrinology 2003149 577-582.

31 Waterlot C, Porchet N, Bauters C, Decoulx M, Wemeau JL, Proye C, Degand PM, Aubert JP, Cortet C \& Dewailly D. Type 1 multiple endocrine neoplasia (MEN1): contribution of genetic analysis to the screening and follow-up of a large French kindred. Clinical Endocrinology 199951 101-107. 
32 Burgess JR, Shepherd JJ, Parameswaran V, Hoffman L \& Greenaway TM. Spectrum of pituitary disease in multiple endocrine neoplasia type 1 (MEN 1): clinical, biochemical, and radiological features of pituitary disease in a large MEN 1 kindred. Journal of Clinical Endocrinology and Metabolism $1996812642-2646$.

33 Langer P, Cupisti K, Bartsch DK, Nies C, Goretzki PE, Rothmund M \& Roher HD. Adrenal involvement in multiple endocrine neoplasia type 1. World Journal of Surgery 200226 891-896.

34 Burgess JR, Harle RA, Tucker P, Parameswaran V, Davies P, Greenaway TM \& Shepherd JJ. Adrenal lesions in a large kindred with multiple endocrine neoplasia type 1. Archives of Surgery 1996 131 699-702.

35 Barzon L, Pasquali C, Grigoletto C, Pedrazzoli S, Boscaro M \& Fallo F. Multiple endocrine neoplasia type 1 and adrenal lesions. Journal of Urology 2001166 24-27.

36 Teh BT, Zedenius J, Kytola S, Skogseid B, Trotter J, Choplin H, Twigg S, Farnebo F, Giraud S, Cameron D, Robinson B, Calender A, Larsson C \& Salmela P. Thymic carcinoids in multiple endocrine neoplasia type 1. Annals of Surgery 1998228 99-105.

37 Ferolla P, Falchetti A, Filosso P, Tomassetti P, Tamburrano G, Avenia N, Daddi G, Puma F, Ribacchi R, Santeusanio F, Angeletti G \& Brandi ML. Thymic neuroendocrine carcinoma (carcinoid) in multiple endocrine neoplasia type 1 syndrome: the Italian series. Journal of Clinical Endocrinology and Metabolism $2007 \mathbf{9 0}$ 2603-2609.

38 Sachithanandan N, Harle RA \& Burgess JR. Bronchopulmonary carcinoid in multiple endocrine neoplasia type 1. Cancer 2005 103 509-515.
39 Asgharian B, Chen YJ, Patronas NJ, Peghini PL, Reynolds JC, Vortmeyer A, Zhuang Z, Venzon DJ, Gibril F \& Jensen RT. Meningiomas may be a component tumor of multiple endocrine neoplasia type 1. Clinical Cancer Research 200410 869-880.

40 Doherty GM, Olson JA, Frisella MM, Lairmore TC, Wells SA, Jr \& Norton JA. Lethality of multiple endocrine neoplasia type 1. World Journal of Surgery 199822 581-586.

41 Dean PG, Van Heerden JA, Farley DR, Thompson GB, Grant CS, Harmsen WS \& Ilstrup DM. Are patients with multiple endocrine neoplasia type 1 prone to premature death? World Journal of Surgery 200024 1437-1441.

42 Majewski JT \& Wilson SD. The MEA-1 syndrome: an all or none phenomenon? Surgery $1979 \mathbf{8 6} 475-484$.

43 Vasen HF, Lamers CB \& Lips CJ. Screening for the multiple endocrine neoplasia syndrome type 1: a study of 11 kindreds in the Netherlands. Archives of Internal Medicine 1989149 2717-2722.

44 Ebeling T, Vierimaa O, Kytl S, Leisti J \& Salmela PI. Effect of multiple endocrine neoplasia type 1 (MEN1) gene mutations on premature mortality in familial MEN1 syndrome with founder mutations. Journal of Clinical Endocrinology and Metabolism 2004 $893392-3396$

Received 26 March 2007

Accepted 28 May 2007 